\title{
Readiness of independency in health care management for young adults with cerebral palsy
}

\author{
Zane Rozkalne ${ }^{1,2, *}$, Maksims Mukans ${ }^{1}$, and Anita Vetra $^{1,2}$ \\ ${ }^{1}$ Rīga Stradinsš University, Riga, Latvia \\ ${ }^{2}$ Children's Clinical University Hospital, Riga, Latvia
}

\begin{abstract}
Transition from paediatric to adult health care services is a crucial process for young adults with long-term medical conditions and well organized and coordinated transition process has been strongly highlighted. The aims of this research were to assess the young adults with cerebral palsy overall readiness for adult life, the independency in health care management and independency impacting factors. Eighty young adults (age range 16-21 years) with $\mathrm{CP}$ and normal or slightly decreased mental function participated. There were done "face-to-face" structured interviews using the Rotterdam Transition Profile and the Transition Readiness Assessment Questionnaire also the characteristics of participants were obtained. It was revealed that young adults with cerebral palsy show low levels of participation in almost all domains of transition to adult life, the level of attendance of rehabilitation services is not sufficient, and the level of independency for young adults with $\mathrm{CP}$ in health care management is between phases of preparation and action. The most impacting factor for independency in health care management was found to be the cognitive status.
\end{abstract}

Key words: cerebral palsy, transition age, health care, young adult.

\section{Introduction}

It has been long thought that cerebral palsy $(\mathrm{CP})$ is a medical condition more attributed to paediatric care, even though most persons with $\mathrm{CP}$ now survive to adulthood [1]. The prevalence of $\mathrm{CP}$ in Europe has been estimated 2 per 1000 live births [2]. Although the neurological injury causing $\mathrm{CP}$ is defined as non-progressive, the musculoskeletal, neurological and mental conditions worsen in the course of time [3-5]. Adults with $\mathrm{CP}$ face health problems such as decreased mobility and self-care [6], hypoactivity [7], chronic pain [3, 8], sarcopenia [9, 10], spasticity [11, 12], musculoskeletal deformities (e.g., articular contractures [12, 13], osteopenia [14], degenerative arthritis [14, 15], deformities of hips [16, 17], knees [16, 18], ankles [12, 19], feet [16, 17] and spine [20-22], epilepsy [3], genitourinary problems [16, 23] and depression and anxiety [24]. It has been proven that as the age for persons with $\mathrm{CP}$ progresses also the use of certain medication (respectively, analgesic, antispastic, and psychotropic drugs in ambulatory patients and psychotropic, antispastic, antiepileptic, and digestive drugs in non-ambulatory patients)

\footnotetext{
* Corresponding author: Z_Rozkalne@inbox.Iv
} 
increases [3]. However, the physical medicine and rehabilitation doctor follow-up, the use of orthoses, and receiving rehabilitation decreases with age [3]. Young adults with CP have reported having too few information about their medical condition [25] and that there is a lack of real life opportunities of becoming independent [26]. Unsuccessful transition to adult life may lead to unnecessary lifelong dependency, unemployment and low quality of life [27, 28]. The transition from paediatric to adult health care is crucial process for persons with $\mathrm{CP}$ [29-34] and specific therapeutic approach is essential [35-38]. The aims of this research were to assess young adults with $\mathrm{CP}$ overall readiness for transition to adult life, the readiness of independency in health care management and the factors having impact on readiness for independency in health care management.

\section{Material and methods}

\subsection{Study design}

The design of the study was a cross-sectional, non-experimental research.

\subsection{Study sample}

Participants were searched through the data basis of Children's Clinical University Hospital and through open invitations in smaller rehabilitation centres. "Face-to-face" structured interviews using the assessment scales and questionnaires were done from October 2017 till June 2018. Permissions from Ethics Committee of Rīga Stradiņš University (August 2016) and from Children's Clinical University Hospital (July 2016) were received. Before signing the consent form, potential participants and their parents read the explanation form of the research and received answers to any questions concerning the participation. For participants under the age of 18 the consent form was signed by the legal representative (all cases one of the parents). The inclusion criteria were: young adults aged 16-21 years, diagnosed with cerebral palsy (G80-G83, International Statistical Classification of Diseases and Related Health Problems, $10^{\text {th }}$ revision), with normal or slightly decreased cognitive status and able to understand the research procedure. Exclusion criteria were: not actually having cerebral palsy (having other cause of the paresis), severe overall physical and cognitive status (MMSE less than 24 points), not living in or coming from family (living in social institution), not living in Latvia, was not possible to gain contact information, not answering to phone call over three times, dead. Two hundred twenty - five potential participants were identified. Considering exclusion criteria and having the will to participate, a total of 80 persons participated.

\subsection{Measures}

For the characteristics of participants (age, gender, type of cerebral palsy, status of speech, vision, hearing, epilepsy, the need of assistant, place of living, level of income, parent status, number of siblings) we used a structured descriptive questionnaire. Type of cerebral palsy was detected through participants' medical records. Sever problems with speech, vision and hearing were detected if others often cannot understand the person's speech and/or the participant's health status was not fully compensated with medical assistive devices (e.g. glasses, hearing aids). Having epilepsy was approved if the person was using antiepileptic drugs prescribed by doctor. Level of average income to a household was defined as 1017.60eurper month (index of year 2016) [39]. "Brought up by both parents" was marked as "yes" even if one of the parents was a step-parent and as "no" if only one parent raised the participant. 


\subsubsection{Functional status}

The gross motor function was assessed using Gross Motor Function Classification System (GMFCS) [40], which is a five-level classification system, where the fifth level (person is transported in a manual wheelchair) is the most sever and first level (person walks without limitations) is the least. The manual abilities were assessed using Manual Ability Classification System (MACS) [41], which also is a five-level classification system, where the fifth level (person does not handle objects and has severely limited ability to perform even simple actions) is the most sever and the first (person handles objects easily and successfully) - the least. The cognitive status was assessed with Mini-Mental State Examination (MMSE) [42], in which the maximum score of points is 30 and the less points a participant receives the more cognitive impairments he/she might have, whereas 24-30 points indicate none or some/uncertain cognitive deficit.

\subsubsection{Transition process to adult life, the Rotterdam Transition Profile}

The readiness for transition to adult life was assessed using the Rotterdam Transition Profile (RTP) [43]. It is a ten transitional domain assessment tool. First seven domains are applied to measure participation and the last three - health care. The assessment of each domain is ranged in three or four phases: phase 0 - the young adult has no experience in a particular field, phase 1 - the young adult is dependent on adults, phase $2-$ the young adult is experimenting and orientating towards a more independent life, phase 3 - the young adult has achieved more-or-less independence and autonomy. The total score of RTP is 30 points the more points a participant has received the more independent and autonomous he or she is.

\subsubsection{Readiness of independency in health care management, the Transition Readiness Assessment Questionnaire}

The readiness of independency in health care management was assessed using the Transition Readiness Assessment Questionnaire (TRAQ) [44]. The TRAQ consists of 20 questions evaluating: medication managing, appointment keeping, tracking health issues, talking with providers and managing daily activities. Each question is scored from 1-5 points, describing the independency level of health care task managing: 1 - No, I do not know how (primary idea), 2 - No, but I want to learn (intent), 3 - No, but I am learning to do this (preparation), 4 - Yes, I have started doing this (action), 5 - Yes, I always do this when I need to (maintenance). The total score of TRAQ is 100 points - the bigger score, the better health care management.

\subsection{Statistical analysis}

Statistical analysis was conducted using SPSS software (IBM SPSS Statistics, v. 23.0, Chicago, IL, USA). The sample was tested for the normality of distribution of the measurements of scales and age by the means of Shapiro-Wilk test. As the sample did not reveal normal distribution, quantitative data was in median $(\mathrm{Me})$ with inter-quartile range (IQR) and non -parametric statistics were performed. Mann-Whitney U test for interval data comparison, Wilcoxon test for time course of interval data, Spearman rho for correlation of interval data, Pearson chi square or Fisher's exact test for categorical data. TRAQ data was divided by median of $\leq 3.00$ points and $\geq 3.01$ points to find the impact of factors: characteristics of participants, functional status, and the readiness for transition to adult 
life. The correlation analysis was done with TRAQ groups to find the strongest association with the impacting factors. Correlation coefficient interpretation: up to $| \pm 0.19|$ very weak, $| \pm 0.20|-| \pm 0.39|$ weak, $| \pm 0.40|-| \pm 0.59|$ moderate, $| \pm 0.60|-| \pm 0.79|$ strong, $| \pm 0.80|-| \pm 0.999|$ very strong [45]. Adjusted residual was marked as significant with value more than $| \pm 1.96|$. Binary logistic regression analysis was done for separate impacting factor to find best (Wald criterion and percentage predicted probability) association with TRAQ data. Second time Binary logistic regression analysis was done for multivariate impacting factors to find most exact and strongest impacting factor. Criterion of choice was Wald, significance $p<0.05$ and odds ratio. In all analyses $p<0.05$ was significant. Graphs were done in SPSS software or MS office Excel (2010).

\section{Results}

\subsection{Characteristics of the study sample}

Table 1 presents the personal characteristics, type of cerebral palsy and the functional level of the 80 young adults aged 16 to 21 years with cerebral palsy who participated in the study. The median age was 18 (IQR 20-17) years and 41\% percent were men. Thirty-four percent of the participants had quadriplegia, 74\% had high level of gross motor function and 70\% had high level of manual ability (GMFCS and MACS level I or II). Fifty percent of the participants had full or almost full score of the MMSE (29-30 points), indicating normal cognitive status and $16 \%$ had severe speech problems. The need of an assistant marked $52 \%$ of the participants. For $38 \%$ of the participants the place of living was town (other than capital city) and $61 \%$ had the income level below the average. Seventy-one percent of the participants were brought up by both parents and $66 \%$ had one sibling.

\subsection{Transitional process to adult life}

The outcomes of the RTP (see Fig. 1) show the general phases of the transition process of the participants.

\subsection{Readiness of independency in health care management and the impacting factors}

Table 2 demonstrates participants' median values of TRAQ, grouped in five health care management related themes.

The median value of the TRAQ score for women was 3.5 (IQR 4.4-3.0) and for men 3.3 (IQR 4.1-2.6). The median values in relation to participants' age, functional and cognitive level are demonstrated in Fig. 2.

To analyze the outcomes of the TRAQ and the outcome impacting factors the score was divided in two groups: $\leq 3.00$ points, group I(the participant is rather in passive than in active phase of task managing) and $\geq 3.01$ points, group II (the participant is rather in active than in passive phase of task managing).The statistical significance of the impacting factor on the participants' appearance in group I or group II was tested with Mann-Whitney U tests and for dichotomous parameters Pearson chi square tests. Person chi square was also done if the data was more demonstrative with this method (factors - Need of an assistant and Level of income) and if $p$-value was not significant, but in some categories adjusted residual was (factors- Level of income and Finance) (see Table 3).

Statistically significant were found to be the level of GMFCS, MACS, MMSE, whether the participant had or had not severe speech problems and the need of an assistant. When 
Table 1. Characteristics of the study participants $(n=80)$.

\begin{tabular}{|c|c|c|c|}
\hline Age in years, Me (IQR) & \multicolumn{2}{|r|}{$18(20-17)$} & \\
\hline \multicolumn{4}{|l|}{ Gender, n (\%) } \\
\hline Men & \multicolumn{2}{|r|}{$41(51)$} & \\
\hline Women & \multicolumn{2}{|r|}{$39(49)$} & \\
\hline Type of CP, n (\%) & \multicolumn{3}{|c|}{ MMSE, n (\%) } \\
\hline Quadriplegia & $27(34)$ & 30 points & $17(21)$ \\
\hline Diplegia & $24(30)$ & 29 points & $23(29)$ \\
\hline Hemiplegia & $16(20)$ & 28 points & $8(10)$ \\
\hline Other & $13(16)$ & 27 points and less & $32(40)$ \\
\hline GMFCS, n (\%) & \multicolumn{3}{|c|}{ MACS, n (\%) } \\
\hline Level I & $35(44)$ & Level I & $23(29)$ \\
\hline Level II & $24(30)$ & Level II & $33(41)$ \\
\hline Level III & $13(16)$ & Level III & $16(20)$ \\
\hline Level IV & $8(10)$ & Level IV & $8(10)$ \\
\hline Level V & $0(0)$ & Level V & $0(0)$ \\
\hline Severe problems with speech, $\mathrm{n}(\%)$ & \multicolumn{2}{|c|}{ no 67 (84) yes $13(16)$} & \\
\hline Severe problems with vision, $\mathrm{n}(\%)$ & \multicolumn{2}{|c|}{ no 73 (91) yes 7 (9) } & \\
\hline Severe problems with hearing, $\mathrm{n}(\%)$ & \multicolumn{2}{|c|}{ no 79 (99) yes $1(1)$} & \\
\hline Epilepsy, n (\%) & \multicolumn{2}{|c|}{ no $72(90)$ yes $8(10)$} & \\
\hline \multicolumn{4}{|l|}{ Need of an assistant, $\mathrm{n}(\%)$} \\
\hline No & \multicolumn{2}{|r|}{$38(48)$} & \\
\hline Only for transportation & \multicolumn{2}{|r|}{$25(31)$} & \\
\hline All the time outside the home & \multicolumn{2}{|r|}{$17(21)$} & \\
\hline \multicolumn{4}{|l|}{ Place of living, $\mathrm{n}(\%)$} \\
\hline Capital city & \multicolumn{2}{|r|}{$29(36)$} & \\
\hline Other town & \multicolumn{2}{|r|}{$30(38)$} & \\
\hline Rural area & \multicolumn{2}{|r|}{$21(26)$} & \\
\hline \multicolumn{4}{|l|}{ Level of income, $\mathrm{n}(\%)$} \\
\hline Below average & \multicolumn{2}{|r|}{$49(61)$} & \\
\hline Average & \multicolumn{2}{|r|}{$18(23)$} & \\
\hline Above average & \multicolumn{2}{|r|}{$13(16)$} & \\
\hline Brought up by both parents, n (\%) & \multicolumn{2}{|c|}{ no 23 (29) yes 57 (71) } & \\
\hline Number of siblings $>1, \mathrm{n}(\%)$ & \multicolumn{2}{|c|}{ no 53 (66) yes 27 (34) } & \\
\hline
\end{tabular}

testing the impact of the scores of RTP on the participants' appearance in group I or group II, significant were found to be almost all the domains of RTP, except for Rehabilitation services. The correlation analysis was made to detect the most associated factors. For further binary logistic regression were chosen factors with $r_{s}>0.39$ (see Table 4).

The impacting factors with the score of Wald >10.00 (MMSE 17.50, Transportation 15.92, Total score of RTP 14.13 and Leisure (social activities) 12.39) were analyzed in binary logistic regression model of equation (see Table 5).

The only impacting factor with $p<0.01$ was the MMSE - level of participants' cognitive status (OR 2.27, 95\% CI 1.36-3.79). Model correctly classified $85 \%$ of cases. 


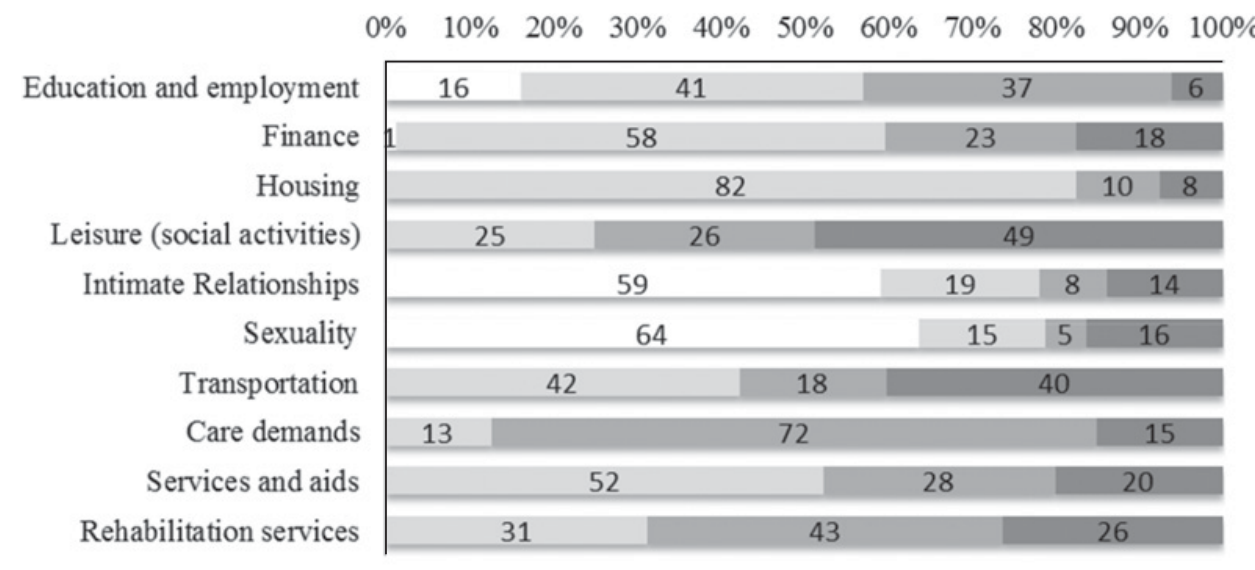

Phase $0=$ Phase $1 \rrbracket$ Phase $2 \approx$ Phase 3

Figure 1. Percentage of participants in the transitional phases (the Rotterdam Transition Profile): 0 no experience, 1 - dependent on parents, 2 - experimenting and orientating, 3 - independence and autonomy.

Table 2. Median values of TRAQ.

\begin{tabular}{lcccc}
\hline TRAQ themes & $<18$ y (IQR) & $\geq 18$ y (IQR) & All (IQR) & $p$-value* \\
\hline Managing Medications & $3.0(3.8-2.0)$ & $3.6(4.8-2.8)$ & $3.5(4.3-2.5)$ & $<0.01$ \\
Appointment Keeping & $2.6(3.0-2.0)$ & $3.0(4.0-2.4)$ & $2.9(3.9-2.2)$ & $<0.05$ \\
Tracking Health Issues & $3.0(3.8-2.3)$ & $3.3(4.1-2.5)$ & $3.3(4.0-2.5)$ & 0.23 \\
Talking with Providers & $4.5(5.0-4.0)$ & $5.0(5.0-4.0)$ & $5.0(5.0-4.0)$ & 0.25 \\
Managing Daily Activities & $4.7(5.0-3.3)$ & $4.7(5.0-4.0)$ & $4.7(5.0-4.0)$ & 0.63 \\
TRAQ total & $3.3(3.6-2.8)$ & $3.6(4.4-3.0)$ & $3.5(4.2-2.9)$ & $<0.05$ \\
\hline
\end{tabular}

*Median differences' significance associated with participants' age (minor vs. adult).

Y: years, IQR: interquartile range, TRAQ: Transition Readiness Assessment Questionnaire.

\section{Discussion}

This is the first study in Latvia that measures the readiness for transition to adult life and the impacting factors for independency in health care management for persons with CP.

We have demonstrated the levels of transitional phases according to the RTP for the young adults with $\mathrm{CP}$ at the process of becoming independent and autonomous. At the level of education and employment we found that almost one quarter of participants were not learning or having a job, and at the level of financial independency more than half were still dependent on parents/care takers. Less than one fifth of participants were orientating or already obtaining some independency in housing activities. Only half of the participants were able to spend time on leisure activities outside home having no restrictions on whether it is day time or late evening. More than half of the participants had completely none experience in intimate and sexual relationships. Also, more than half of the participants were fully or partially dependent on parents/care givers at the transportation domain. Seventy-two percent of participants claimed that they take part in decision-making about their health care management, but again - more than half of finding services and aids were done by parents/care givers. Even though persons with $\mathrm{CP}$ require throughout life health care, $43 \%$ had not received any rehabilitation 
Table 3. Values of factors in comparison to TRAQ group I and group II.

\begin{tabular}{|c|c|c|c|c|}
\hline \multirow[t]{2}{*}{ Factors } & \multirow[t]{2}{*}{$p$-value } & \multirow[t]{2}{*}{ Adj.res. } & \multicolumn{2}{|c|}{ TRAQ } \\
\hline & & & $\leq 3.00$ & $\geq 3.01$ \\
\hline Gender & & $<1.96$ & & \\
\hline Age & 0.44 & & & \\
\hline GMFCS, level 1-5 (IQR) & $<0.01$ & & $2(3-2)$ & $1(2-1)$ \\
\hline MACS, level 1-5 (IQR) & $<0.01$ & $3(3-2)$ & $2(2-1)$ & \\
\hline MMSE, points 30-24 (IQR) & $<0.01$ & & $26(28-25)$ & $29(30-27)$ \\
\hline Severe problems with speech, $n(\%)$ & & $>1.96$ & & \\
\hline no & & & $16(20)$ & $51(64)$ \\
\hline yes & & & $8(10)$ & $5(6)$ \\
\hline Severe problems with vision & & $<1.96$ & & \\
\hline Severe problems with hearing & & $<1.96$ & & \\
\hline Epilepsy & & $<1.96$ & & \\
\hline Need of an assistant, $n(\%)$ & $<0.01$ & $>1.96$ & & \\
\hline No & & & 2(3) & $36(45)$ \\
\hline Only for transportation & & & $16(20)$ & $9(11)$ \\
\hline All the time outside the home & & & $6(7) *$ & $11(14) *$ \\
\hline Place of living & 0.88 & & & \\
\hline Level of income, $n(\%)$ & 0.14 & $<1.96$ & & \\
\hline Below medium & & & $17(21)^{*}$ & $32(40)^{*}$ \\
\hline Medium & & & $6(8) *$ & $12(15)^{*}$ \\
\hline Above medium & & & $1(1)^{* *}$ & $12(15)^{* *}$ \\
\hline Brought up by both parents & & $<1.96$ & & \\
\hline Number of siblings & & $<1.96$ & & \\
\hline \multicolumn{5}{|l|}{ RTP, phases 0-3 (IQR) } \\
\hline Education and employment & 0.02 & & $1(2-0)$ & $2(2-1)$ \\
\hline Finance, $n(\%)$ & 0.13 & $>1.96$ & & \\
\hline Phase 0 & & & $0(0) *$ & $1(1)^{*}$ \\
\hline Phase 1 & & & $17(21)^{*}$ & $30(38)^{*}$ \\
\hline Phase 2 & & & $6(8)^{*}$ & $12(15)^{*}$ \\
\hline Phase 3 & & & $1(1)$ & $13(16)$ \\
\hline Housing & 0.01 & & $* * *$ & $1(2-1)$ \\
\hline Leisure (social activities) & $<0.01$ & & $2(2-1)$ & $3(3-2)$ \\
\hline Intimate Relationships & $<0.01$ & & $0(0-0)$ & $1(2-0)$ \\
\hline Sexuality & $<0.01$ & & $0(0-0)$ & $0(2-0)$ \\
\hline Transportation & $<0.01$ & & $1(1-1)$ & $3(3-1)$ \\
\hline Care demands & $<0.01$ & & $2(2-1)$ & $2(2-2)$ \\
\hline Services and aids & $<0.01$ & & $1(1-1)$ & $2(3-1)$ \\
\hline Rehabilitation services & 0.12 & & & \\
\hline Total score of RTP, points 6-30 (IQR) & $<0.01$ & & 11(14-9) & $17(21-13)$ \\
\hline
\end{tabular}

*Adj. res. $<1.96, * *$ adj.res. $=1.9, * * *$ constant when TRAQ $\leq 3.00$.

Adj.res.: adjusted residual, IQR: interquartile range, RTP: Rotterdam Transition Profile, Phase 0 - no experience, Phase 1 - dependent on parents, Phase 2 - experimenting and orientating, Phase 3 -independence and autonomy (RTP). 

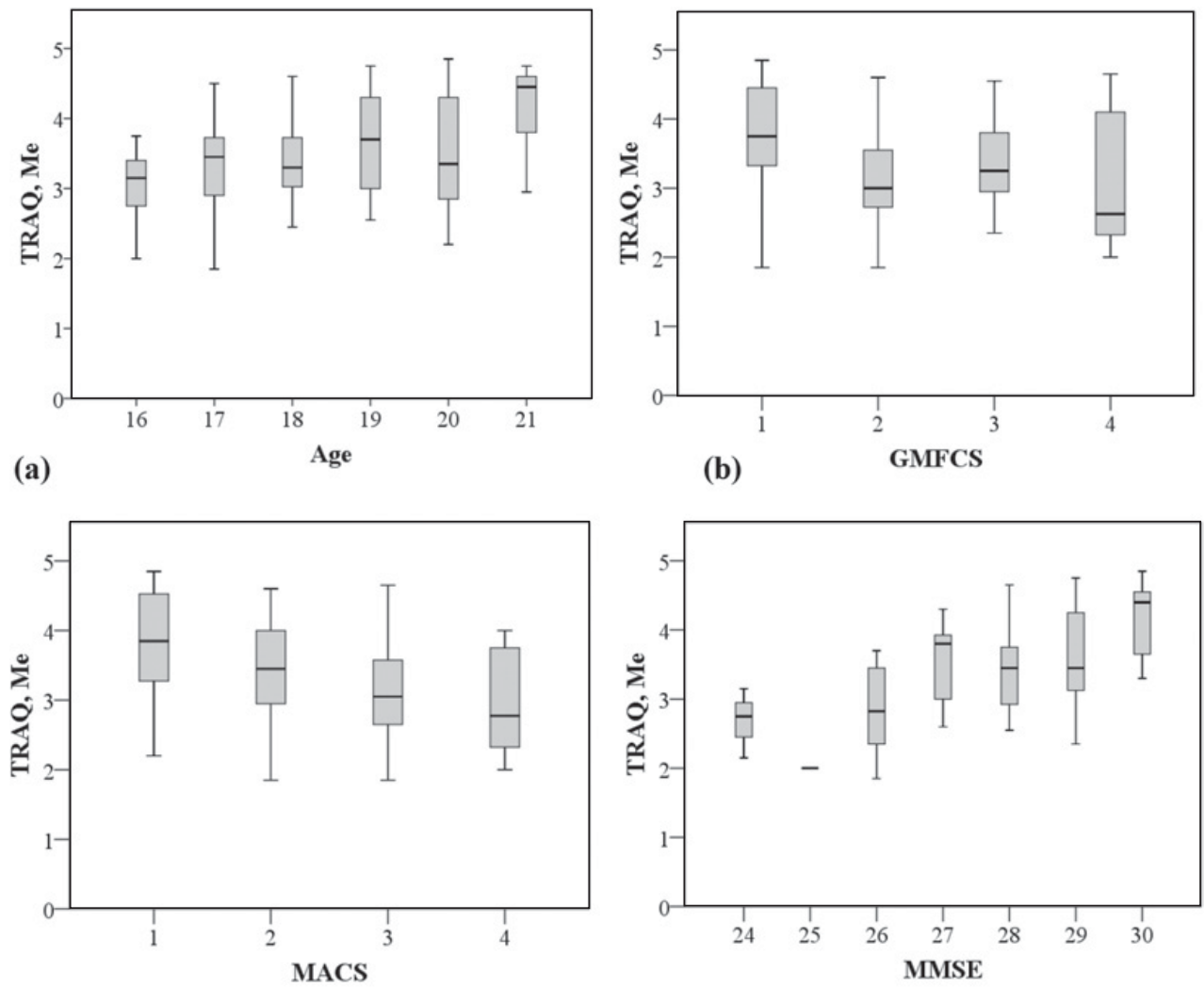

(c)

(d)

Figure 2. Median values of the Transition Readiness Assessment Questionnaire (TRAQ) total score impacted by: (a) age, (b) gross motor function (Gross Motor Function Classification System, GMFCS), (c)manual abilities (Manual Ability Classification System, MACS), and (d) cognitive status (MiniMental State Examination, MMSE).

services during the past year. These results are closely associated with findings in previous researches done in the Netherlands [6, 43].

In our research we analyzed the readiness of independency in health care management as the median scores of TRAQ. The lowest scores were found in thematic block "Appointment keeping" with median value 2.9 which indicates an inactive phase in making appointments, following-up on referral for test or check-ups, health change related call making to specialists etc. Thematic block "Talking with Providers" received the highest median score (Me 5.0). This was similarly seen also in the results of RTP - young adults with CP are being involved in discussions, but the real action is done by others (parents/care takers). It has been previously revealed that the assessment of health care management with generic and condition-specific measures can unfold targeted interventions and specific supports in achieving independence [46]. Our results for the total median value of TRAQ are found to be lower than those of previous research done in Latvia by L. Baranova and A. Vētra, 2016 [47] (Me 3.6 vs. 4.3, age 18-21 years). This could be explained by the fact that our research included only participants with CP and even those who had slightly decreased cognitive status. Research done by L. Baranova and A. Vētra included participants with functional limitations, not only with $\mathrm{CP}$, although the cognitive status of participants was not described. 
Table 4. Correlations and binary logistic regressions of the impacting factors.

\begin{tabular}{lcccc}
\hline & Spearman's rho & Wald & Predicted, \% & OR (95\% CI) \\
\hline GMFCS & -0.41 & 9.98 & 73 & $0.43(0.26-0.73)$ \\
MACS & -0.36 & & & \\
MMSE & 0.53 & 17.50 & 79 & $2.18(1.51-3.13)$ \\
Severe problems with speech & -0.30 & & & \\
Need of an assistant & -0.40 & 9.26 & 64 & $0.36(0.19-0.70)$ \\
Education and employment & 0.26 & & & \\
Housing & 0.30 & & & \\
Leisure (social activities) & 0.43 & 12.39 & 73 & $3.19(1.67-6.09)$ \\
Intimate Relationships & 0.36 & & & \\
Sexuality & 0.39 & & & \\
Transportation & 0.52 & 15.92 & 75 & $5.16(2.31-11.56)$ \\
Care demands & 0.34 & & & \\
Services and aids & 0.36 & & & \\
Total score of RTP & 0.53 & 14.13 & 76 & $1.43(1.19-1.73)$ \\
\hline$p<0.05$. & & & & \\
OR: odds ratio, CI: confidence interval. & & & &
\end{tabular}

Table 5. Binary logistic regression equation* of the impacting factors.

\begin{tabular}{lccc}
\hline & Wald & $p$-value & OR $(95 \% \mathrm{CI})$ \\
\hline MMSE & 9.89 & $<\mathbf{0 . 0 1}$ & $2.27(1.36-3.79)$ \\
Leisure (social activities) & 0.38 & 0.54 & $1.37(0.51-3.67)$ \\
Transportation & 0.68 & 0.41 & $1.65(0.50-5.41)$ \\
Total score of RTP & 3.46 & 0.06 & $1.37(0.98-1.91)$ \\
\hline
\end{tabular}

*85.0 percentage correct.

In our study it was found that the highest scores of TRAQ median were associated with the increase of participants' age, gross motor function, manual abilities and cognitive status. A linear increase was detected in the association with manual abilities. Other factors demonstrated non-linear increase of the TRAQ median score. It might be induced that a person with lower gross motor function have relatively high independency in health care management, and a person at an older age might not be as independent as age-matched peers because of other impacting factors. This highlights the idea that none of these factors can be taken as the only one when assessing young adults with $\mathrm{CP}$ readiness in health care management. It has been previously revealed that assessing the person, e.g., by age is not the only determinant of person's readiness to be transited to adult health care [48].

To find out which of the factors have the most significant impact on independency in health care management we divided the TRAQ scores in two groups: $\leq 3.00$ (rather passive phase, less independency) and $\geq 3.01$ (rather active phase, more independency). It was detected that level of GMFCS, MACS, MMSE, having or not having severe speech problems or the need for an assistant and having income that exceeds the average have an impact on the participant's presents in one of the groups. The more capable the participant was in terms of gross motor or manual function, the less cognitive deficit and severe speech problems he/she had, and the more his/her income exceeded the average, the more he/she was likely to be present in group with TRAQ score $\geq 3.01$. Almost all domains of RTP (except 
for Rehabilitation services) and the total score of RTP had an impact on the participants' presence in one of the groups. Respectively, the higher score of RTP domains and the total score of RTP the more likely for the participant to be in a rather active phase of independency in health care management. For the overall readiness to adult life for persons with $\mathrm{CP}$ and normal cognitive status it has been proven that there are associations with participant's age, gross motor functioning (GMFCS), manual abilities (MACS) and level of education [43]. We did not find the participants' gender, age, having or not severe problems with vision or hearing, having or not epilepsy, the place of living, being brought up by one or both parents, coming or not from a large family as an impacting factor on participants' presence in one of the groups.

The most correlating factors for the independency in health care management were found to be level of MMSE, level of leisure (social activities), independency in transportation and the total score of RTP. Suggesting that if the person has higher levels of cognitive status, ability to participate in leisure activities, arrange transportation and has higher level of overall readiness to adult life, he or she can achieve greater independency in health care management. After the binary logistic regression equation, the most impacting factor on whether the participant will receive TRAQ score $\geq 3.01$, was detected to be the level of cognitive status (MMSE). Cognitive status has been found as an impacting factor also for other aspects of life for persons' with CP, e.g., employment [49], communication, receiving support and accessing services [50].

Limitations of this study include not having an able-bodied control group as a reference and the fact that RTP and TRAQ are similar in their aim of an assessment, therefore some results were overlapping. This is planned to be taken into account in the future research.

\section{Conclusions}

Young adults with cerebral palsy show low levels of participation in almost all domains of transition to adult life. Regardless of the fact that persons with $\mathrm{CP}$ need throughout life health care, the level of attendance of rehabilitation services is not sufficient. Even though young adults with $\mathrm{CP}$ seem to take part in decision-making and the increase of independency has been strongly highlighted, the level of independency for young adults with $\mathrm{CP}$ in health care management is between phases of preparation and action. The most impacting factor for independency in health care management was found to be the cognitive status, which should be considered when assessing person's readiness for transition to adult health care.

\section{References}

[1] E. Blair, L. Watson, N. Badawi, F.J. Stanley, Life expectancy among people with cerebral palsy in Western Australia. Dev. Med. Child. Neurol. 43(8), 508-15 (2001)

[2] Prevalence and characteristics of children with cerebral palsy in Europe. Dev. Med. Child. Neurol. 44(9), 633-40 (2002)

[3] M. Roquet, R. Garlantezec, O. Remy-Neris, E. Sacaze, P. Gallien, J. Ropars, et al., From childhood to adulthood: health care use in individuals with cerebral palsy. Dev. Med. Child. Neurol. 60(12), 1271-7 (2018)

[4] M.E. Roebroeck, R. Jahnsen, C. Carona, R.M. Kent, M.A. Chamberlain, Adult outcomes and lifespan issues for people with childhood-onset physical disability. Dev. Med. Child. Neurol. 51(8), 670-8 (2009) 
[5] L.L. Tosi, N. Maher, D.W. Moore, M. Goldstein, M.L. Aisen, Adult swith cerebral palsy: a workshop to define the challenges of treating and preventing secondary musculoskeletal and neuromuscular complications in this rapidly growing population. Dev. Med. Child. Neurol. England. 52(Suppl 4), 2-11 (2009)

[6] C. Nieuwenhuijsen, M. Donkervoort, W. Nieuwstraten, H.J. Stam, M.E. Roebroeck, Experienced problems of young adults with cerebral palsy: targets for rehabilitation care. Arch. Phys. Med. Rehabil. 90(11), 1891-7 (2009)

[7] C. Nieuwenhuijsen, W.M. van der Slot, A. Beelen, J.H. Arendzen, M.E. Roebroeck, H.J. Stam, et al., Inactive lifestyle in adults with bilateral spastic cerebral palsy. J. Rehabil. Med. 41(5), 375-81 (2009)

[8] R. Jahnsen, L. Villien, G. Aamodt, J.K. Stanghelle, I. Holm, Musculoskeletal pain in adults with cerebral palsy compared with the general population. J. Rehabil. Med. 36(2), 78-84 (2004)

[9] A. Shortland, Muscle deficits in cerebral palsy and early loss of mobility: can we learn something from our elders? Dev. Med. Child. Neurol. 51(Suppl 4), 59-63 (2009)

[10] M.D. Peterson, P.M. Gordon, E.A. Hurvitz, Chronic disease risk among adults with cerebral palsy: the role of premature sarcopoenia, obesity and sedentary behaviour. Obes. Rev. 14 (2), 171-82 (2013)

[11] Surveillance of cerebral palsy in Europe: a collaboration of cerebral palsy surveys and registers. Surveillance of Cerebral Palsy in Europe (SCPE). Dev. Med. Child. Neurol. 42(12), 816-24 (2000)

[12] K.P. Murphy, The adult with cerebral palsy. Orthop. Clin. North. Am. 41(4), 595-605 (2010)

[13] T.D. Sanger, M.R. Delgado, D. Gaebler-Spira,M. Hallett, J.W. Mink, Classification and definition of disorders causing hypertoniain childhood. Pediatrics. 111(1), e89-97 (2003)

[14] D.G. Whitney, E.A. Hurvitz, M.J. Devlin, M.S. Caird, Z.P. French, E.C. Ellenberg, et al., Age trajectories of musculoskeletal morbidities in adults with cerebral palsy. Bone. 114, 285-91 (2018)

[15] K.P. Murphy, Cerebral palsy life time care - four musculoskeletal conditions. Dev. Med. Child. Neurol. 51(Suppl 4), 30-7 (2009)

[16] L.B. Green, E.A. Hurvitz, Cerebral palsy. Phys. Med. Rehabil. Clin. N. Am. 18(4), 859-82, vii (2007)

[17] D.S. Morrell, J.M. Pearson, D.D. Sauser, Progressive bone and joint abnormalities of the spine and lower extremities in cerebral palsy. Radiographics. 22(2), 257-68 (2002)

[18] R.L. Lenhart, S.C. Brandon, C.R. Smith, T.F. Novacheck, M.H. Schwartz, D.G. Thelen, Influence of patellar position on the knee extensor mechanism in normal and crouched walking. J. Biomech. 51, 1-7 (2017)

[19] S.H. Schless, F. Cenni, L. Bar-On, B. Hanssen, M. Goudriaan, E. Papageorgiou, et al., Combining muscle morphology and neuromotor symptoms to explain abnormal gait at the ankle joint level in cerebral palsy. Gait Posture. 68, 531-7 (2018)

[20] K. Yoshida, I. Kajiura, T. Suzuki, H. Kawabata, Natural history of scoliosis in cerebral palsy and risk factors for progression of scoliosis. J. Orthop. Sci. 23(4), 649-52 (2018)

[21] J.G. Thometz, S.R. Simon, Progression of scoliosis after skeletal maturity in institutionalized adults who have cerebral palsy. J. Bone Joint. Surg. Am. 70(9), 1290-6 (1988)

[22] T. Sakai, H. Yamada, T. Nakamura, K. Nanamori, Y. Kawasaki, N. Hanaoka, et al., Lumbar spinal disorders in patients with athetoid cerebral palsy: a clinical and biomechanical study. Spine (Phila. Pa. 1976), 31(3), E66-70 (2006) 
[23] B. Samijn, E. VanLaecke, C. Renson, P. Hoebeke, F. Plasschaert, J. VandeWalle, et al., Lower urinary tract symptoms and urodynamic findings in children and adults with cerebral palsy: A systematic review. Neurourol. Urodyn. 36(3), 541-9 (2017)

[24] K.J. Smith, M.D. Peterson, N.E. O'Connell, C. Victor, S. Liverani, N. Anokye, et al., Risk of Depression and Anxiety in Adults With Cerebral Palsy. JAMA Neurol. (2018)

[25] C. Nieuwenhuijsen, Y. van der Laar, M. Donkervoort, W. Nieuwstraten, M.E. Roebroeck, H.J. Stam, Unmet needs and healthcare utilization in young adults with cerebral palsy. Disabil. Rehabil. 30(17), 1254-62 (2008)

[26] M. Freeman, D. Stewart, C.E. Cunningham, J.W. Gorter, "If I had been given that information back then": An interpretive description exploring the information needs of adults with cerebral palsy looking back on their transition to adulthood. Child. Care Health Dev. 44(5), 689-96 (2018)

[27] M.A. Chamberlain, R.M. Kent, The needs of young people with disabilities intransition from paediatric to adult services. Eura. Medicophys. 41(2), 111-23 (2005)

[28] J. Magill-Evans, L. Wiart, J. Darrah, M. Kratochvil, Beginning the transition to adulthood: the experiences of six families with youths with cerebral palsy. Phys. Occup. Ther. Pediatr. 25(3), 19-36 (2005)

[29] E. Bjorquist, E. Nordmark, I. Hallstrom, Living in transition - experiences of health and well-being and the needs of adolescents with cerebral palsy. Child: care, health and development. 41(2), 258-65 (2015)

[30] D. Lariviere-Bastien, E. Bell, A. Majnemer, M. Shevell, E. Racine, Perspectives of young adults with cerebral palsy on transitioning from pediatric to adult health care systems. Semin. Pediatr. Neurol. 20(2), 154-9 (2013)

[31] E. Racine, D. Lariviere-Bastien, E. Bell, A. Majnemer, M. Shevell, Respect for autonomy in the health care context: observations from a qualitative study of young adults with cerebral palsy. Child Care Health Dev. 39(6), 873-9 (2013)

[32] P.Y. Chu, G.R. Maslow, M. vonIsenburg, R.J. Chung, Systematic Review of the Impact of Transition Interventions for Adolescents With Chronic Illnesson Transfer From Pediatric to Adult Healthcare. J. Pediatr. Nurs. 30(5), e19-27 (2015)

[33] K.S. Steinbeck, L. Brodie, S.J. Towns, Transition in chronic illness: Who is going where? J. Paediatr. Child Health. 44(9), 478-82 (2008)

[34] N. Bagatell, D. Chan, K.K. Rauch, D. Thorpe, "Thrust in to adulthood": Transition experiences of young adults with cerebral palsy. Disability and Health Journal. 10(1), 80-6 (2017)

[35] A. Bolger, J. Vargus-Adams, M. McMahon, Transition of Care in Adolescents With Cerebral Palsy: A Survey of Current Practices. Pm. r. 9(3), 258-64 (2017)

[36] M.J. Okumura, M. Saunders, R.S. Rehm, The Role of Health Advocacy in Transitions from Pediatric to Adult Care for Children with Special Health Care Needs: Bridging Families, Provider and CommunityServices. J. Pediatr. Nurs. 30(5), 714-23 (2015)

[37] R. Linroth, Meeting the needs of young people and adults with childhood-onset conditions: Gillette Lifetime Specialty Healthcare. Dev. Med. Child Neurol. 51(Suppl 4), 174-7 (2009)

[38] R. Watson, J.R. Parr, C. Joyce, C. May, A.S. LeCouteur, Models of transitional care for young people with complex health needs: a scoping review. Child Care Health Dev. 37(6), 780-91 (2011)

[39] IIG080. Mājsaimniecību rīcībā esošie ienākumi pēc mājsaimniecības tipa (euro, mēnesī). Available at: https://data1.csb.gov.lv/pxweb/lv/sociala/ sociala__mb_ienakumi/IIG080.px/table/tableViewLayout1/?rxid= 03d1d4fb-19c9-4c7f-b4f9-d8a532aca243. Accessed 17.11.18 
[40] R. Palisano, P. Rosenbaum, S. Walter, D. Russell, E. Wood, B. Galuppi, Development and reliability of a system to classify gross motor function in children with cerebral palsy. Dev. Med. Child Neurol. 39(4), 214-23 (1997)

[41] A.C. Eliasson, L. Krumlinde-Sundholm, B. Rosblad, E. Beckung, M. Arner, A.M. Ohrvall, et al., The Manual Ability Classification System (MACS) fo rchildren with cerebra lpalsy: scale development and evidence of validity and reliability. Dev. Med. Child Neurol. 48(7), 549-54 (2006)

[42] T.N. Tombaugh, N.J. McIntyre, The mini-mental state examination: a comprehensive review. J. Am. Geriatr. Soc. 40(9), 922-35 (1992)

[43] M. Donkervoort, D.J. Wiegerink, J. vanMeeteren, H.J. Stam, M.E. Roebroeck, Transition to adulthood: validation of the Rotterdam Transition Profile for young adults with cerebral palsy and normal intelligence. Dev. Med. Child Neurol. 51(1), 53-62 (2009)

[44] D.L. Wood, G.S. Sawicki, M.D. Miller, C. Smotherman, K. Lukens-Bull, W.C. Livingood, et al., The Transition Readiness Assessment Questionnaire (TRAQ): its factor structure, reliability, and validity. Acad. Pediatr. 14(4), 415-22 (2014)

[45] Spearman's Rank Correlation-Video Tutorial with Dr.Iain Weir. Available at: http: // www.statstutor.ac.uk/resources/uploaded/SpearmanCorrelation/ Tutorial/spearmans.htm. Accessed 17.12.18

[46] S. Warschausky, J.N. Kaufman, W. Schutt, M. Evitts, E.A. Hurvitz, Health selfmanagement, transition readiness and adaptive behavior in persons with cerebral palsy or myelomeningocele. Rehabil. Psychol. 62(3), 268-75 (2017)

[47] L. Baranova, A. Vētra, Funkcionāli ierobežotu jauniešu pāreja uz pieaugušo veselības aprūpes sistēmu: sagatavot̄̄ba un pieredze. RSU Scientific Conference: Riga Stradins University (2016)

[48] F. Campbell, K. Biggs, S.K. Aldiss, P.M. O’Neill, M. Clowes, J. McDonagh, et al., Transition o fcare for adolescents from paediatric services to adult health services. Cochrane Database Syst. Rev. 4, Cd009794 (2016)

[49] S. Rutkowski, E. Riehle, Access to employment and economic independence incerebral palsy. Phys. Med. Rehabil. Clin. N. Am. 20(3), 535-47 (2009)

[50] A. Ali, K. Scior, V. Ratti, A. Strydom, M. King, A. Hassiotis, Discrimination and other barriers to accessing health care: perspectives of patients with mild and moderate intellectual disability and their carers. PLoS. One. 8(8), e70855 (2013) 